\title{
QUALITY OF LIFE PERCEPTIONS OF CAREGIVERS OF INDIVIDUALS WITH INTELLECTUAL DISABILITIES IN THE UNITED STATES AND THE CZECH REPUBLIC
}

\section{Milan Valenta, Jan Michalík, Sharon Raver-Lampman, Anne Michalek}

\begin{abstract}
Caregivers of individuals with disabilities in the United States have been reported to experience additional hardships than families with typical children as they attempt to balance family and work (Parish, Rose, Grinstein-Weiss, Richman, \& Andrews, 2008). In this study, 31 caregivers of individuals with intellectual disabilities from the United States and 225 from the Czech Republic completed a qualitative quality of life survey. Similarities in the two groups were found in reported gains and losses from caregiving responsibilities. Differences in perceived spirituality, personal sense of peace and serenity, life optimism, ability to rejoice in life, personal life perspective, health, financial changes, changes in family social life, feelings of enrichment, family caregiving responsibilities, and attitudes about the future were also revealed. The implications for supporting families through governmental programs and individualized services are discussed.
\end{abstract}

\section{Keywords}

Caregivers' perceptions, caregivers of individuals with intellectual disabilities, comparison of caregivers' attitudes in United States and Czech Republic.

Comparison of Quality of Life Perceptions of Caregivers of Individuals with Special Needs in the United States and the Czech Republic

A disability is a culturally and socially constructed phenomenon in which each society defines the parameters of what is considered "typical" (Linan-Thompson \& Jean, 1997). Frequently parents do not perceive a disability the same way as professionals, especially when the diagnosis involves young children. The literature suggests that parents vary in their reactions, and that most parents go through a period of adjustment, with further adjustments as their child ages (Harden, 2005; Raver, 2009). Although parents and guardians expect to perform caregiving tasks during the upbringing of 
a child, when a child has intellectual impairments, roles and duties may change as caregivers face the possibility that a child may require long-term care beyond the typical child-rearing years (White \& Hastings, 2004; Raina et al., 2005). Caregivers may experience stress and an array of other feelings as they adjust to the demands of caring for someone with special needs while trying to balance the needs of the entire family and work responsibilities (McDonald, Poertner, \& Pierpoint, 1999; Plant \& Sanders, 2007; Raina et al., 2004; Rosenzweig, Brennan, \& Ogilvie, 2002). Providing care for an individual with a disability may drain financial resources and physical and emotional energy (Murphy, Christian, Caplin, \& Young, 2006). Research has shown that caregivers of children with disabilities report increased health and psychological problems when compared to parents of children without disabilities (Florian \& Findler, 2001; Maes, Broekman, Dosen, \& Nauts, 2003). Further, supplementary costs for medical procedures, therapies, and adaptations may increase financial pressures on caregivers, causing more tension (Parish, Rose, Grinstein-Weiss, Richman, \& Andrews, 2008).

\section{Method}

\section{Participants}

Thirty-one caregivers of individuals with intellectual disabilities (e.g., mental retardation, autism) residing in the United States, and 255 caregivers of individuals with intellectual disabilities (labeled as having mental retardation) in the Czech Republic participated in the study. A caregiver was defined as any individual, at least 18 of years of age, who assumed at least $50 \%$ daily caregiving responsibility of an individual with any degree of an intellectual disability. Characteristics of respondents from the United States and the Czech Republic, and the individuals for whom they provided care, are summarized in Table 1. The majority of respondents in both countries were female (U.S. 74.2\%; C.R. 81.3\%) and were responsible for caring for a child (U.S. $77.4 \%$; C.R. $67.56 \%$ ). Most of the caregivers were married or in a partnership (U.S. $58.6 \%$; C.R. $68.9 \%$ ). The majority of respondents from the United States had a college education (61.3\%) while the majority from the Czech Republic had completed secondary school (56.1\%). Respondents from the United States cared for individuals they identified as having intellectual disabilities or mental retardation and/or autism. Those in the Czech Republic cared for individuals defined as mentally retarded which included some with 
Table 1: Characteristics of Caregivers in the United States and Czech Republic and the Family Member Who Received Care

\begin{tabular}{|c|c|c|c|c|c|}
\hline \multirow[t]{2}{*}{ Caregiver } & \multicolumn{2}{|c|}{$\begin{array}{c}\text { Percent of } \\
\text { Respondents }\end{array}$} & \multirow[t]{2}{*}{$\begin{array}{c}\text { Family member who } \\
\text { receives care }\end{array}$} & \multicolumn{2}{|c|}{$\begin{array}{c}\text { Percent of } \\
\text { Respondents }\end{array}$} \\
\hline & $\begin{array}{l}\text { United } \\
\text { States }\end{array}$ & $\begin{array}{c}\text { Czech } \\
\text { Republic } \\
\end{array}$ & & \begin{tabular}{|l|} 
United \\
States \\
\end{tabular} & $\begin{array}{c}\text { Czech } \\
\text { Republic } \\
\end{array}$ \\
\hline \multicolumn{2}{|l|}{ Gender } & & \multicolumn{3}{|l|}{ Relationship to Caregiver } \\
\hline Female & 74.2 & 81.3 & Child & 67.7 & 67.6 \\
\hline \multirow[t]{3}{*}{ Male } & 22.6 & 18.7 & Sibling & 16.1 & 1.3 \\
\hline & & & Relative & 12.9 & 24.0 \\
\hline & & & Not Related/Guardian & 0.0 & 4.4 \\
\hline \multicolumn{3}{|l|}{ Age } & \multicolumn{3}{|l|}{ Age } \\
\hline Up to 20 years & 3.2 & 0.0 & Up to 6 years & 32.3 & 5.3 \\
\hline Up to 30 years & 22.6 & 4.9 & Up to 20 years & 45.2 & 40.4 \\
\hline Up to 40 years & 29.0 & 19.6 & Up to 40 years & 9.7 & 11.6 \\
\hline Up to 50 years & 25.8 & 17.3 & Up to 65 years & 6.5 & 10.7 \\
\hline Up to 60 years & 16.1 & 57.3 & Older than 65 years & 3.2 & 32.0 \\
\hline \multicolumn{3}{|l|}{\begin{tabular}{|c|} 
Living Status \\
\end{tabular}} & \multicolumn{3}{|l|}{\begin{tabular}{|l} 
Disability \\
\end{tabular}} \\
\hline Married/Partner & 48.4 & 68.9 & Mental Retardation & 77.4 & 100.0 \\
\hline Single & 35.5 & 30.7 & Autism/MR & 22.6 & 0.0 \\
\hline \multicolumn{3}{|c|}{ Time caring for family member with disability } & \multicolumn{3}{|l|}{ Severity of Disability } \\
\hline Up to 6 years & 41.9 & 38.7 & Mild-Moderate & 70.9 & 21.8 \\
\hline Up to 10 years & 16.1 & 22.7 & Severe-Profound & 25.8 & 72.9 \\
\hline Up to 15 years & 12.9 & 12.0 & & & \\
\hline Up to 20 years & 19.4 & 12.9 & Facility Attending & & \\
\hline Longer than 30 years & 3.2 & 10.5 & School Program \& At Home & 80.7 & 92.4 \\
\hline \multirow[t]{2}{*}{ No Answer } & 0.0 & 3.5 & Year-round Program & 6.5 & 4.0 \\
\hline & & & Other & 6.5 & 0.0 \\
\hline \multicolumn{3}{|l|}{ Residence } & No Answer & 0.0 & 3.6 \\
\hline In a city & 67.7 & 93.5 & & & \\
\hline In a small town & 29.0 & 2.2 & & & \\
\hline \multicolumn{3}{|l|}{ Education } & & & \\
\hline Primary & 3.2 & 10.2 & & & \\
\hline Secondary & 12.9 & 56.1 & & & \\
\hline Vocational training & 19.4 & 12.4 & & & \\
\hline University & 61.3 & 17.8 & & & \\
\hline \multicolumn{3}{|l|}{ Employmenr Lenght } & & & \\
\hline $0-15$ years & 32.3 & 36.5 & & & \\
\hline 16 and more & 64.6 & 61.3 & & & \\
\hline \multicolumn{3}{|l|}{ Currently Employed } & & & \\
\hline Full-time & 64.5 & 17.8 & & & \\
\hline Part-time & 12.9 & 8.0 & & & \\
\hline No & 19.4 & 71.5 & & & \\
\hline
\end{tabular}


additional health and physical disabilities. The majority of caregivers from the United States indicated that their family members' disability fell in the mild to moderate level of impairment (70.9\%). The largest group receiving care in the Czech Republic was identified to be in the severe to profound level of impairment (72.9\%). Finally, the majority of the American and Czech respondents had been employed for 16 or more years (U.S. $64.6 \%$; C.R. $61.3 \%$ ).

\section{Procedure}

To determine if there were differences in perceptions regarding quality of life issues and concerns between caregivers living in the United States and the Czech Republic, caregivers completed a paper survey by circling the response that most closely matched their opinion or perception. In the United States, the survey was distributed to two educational facilities and two family support groups in the eastern part of Virginia. Names were not placed on the surveys which contained instructions and a self-addressed, stamped envelope so completed surveys could be returned anonymously. In some cases, surveys were placed in an envelope and sealed by the respondent, and then handed to an associate of the research team. In the Czech Republic, surveys were distributed to five special and/or residential schools and two rehabilitation resource centers which were located throughout the country. Respondents completed the survey, sealed it in an envelope to keep it anonymous, and handed it to a representative of the research team. The survey took about 25 minutes to complete, and all participants completed it voluntarily. In the United States, 130 surveys were distributed, with a $23 \%$ return rate. In the Czech Republic, 250 surveys were distributed, with a 90\% return rate. The surveys in the Czech Republic were distributed by administrators of special schools and rehabilitation centers which may have accounted for the higher rate of return in the Czech Republic.

\section{Data Analysis and Instrument}

All responses were calculated into percentages, including demographic information, and then compared by survey item and country. Responses to open-ended, write-in questions were clustered into principal ideas, and then summarized by percentages.

The survey was developed based on a literature review of caregivers' major quality of life indicators, life stressors, collaborations between American and 
Czech colleagues, and field interviews with other caregivers prior to the initiation of the study. Some items from The Family Quality of Life Scale (FQOLS) (Park et al., 2003) were adapted for the instrument. Excluding demographic questions, the survey had a total of 26 items and two open-ended questions, and was divided into two parts. Part I addressed demographic information including the following about the caregiver: gender; marital status; residence in city or small town; age; educational level; length of employment; length of time the respondent had been caring for the identified family member; and current employment status. Further, information about the individual being cared for was gathered: the disability; the severity of the disability; the age of the individual; the relationship of the individual to the respondent; and the identified family member's current educational, work or leisure placement.

Part II was divided into five sections and asked respondents to indicate their emotional, spiritual, social, health, occupational and economic perceptions of their caregiving responsibilities. Section A asked respondents to identify how caring for their family member with a disability had or had not changed certain aspects of their life (e.g., spirituality, altruism). Participants were asked to indicate how these aspects of their life had either "increased", "remained the same", or "had been reduced". Sections B and C probed caregivers' feelings regarding control, fatigue and the social life of their family and how these aspects of their lives had or had not been changed by caregiving responsibilities. Respondents circled one of 4 choices which best matched their perception (e.g., "yes - there was a change", "it is likely there has been a change", "it is likely there has been no change", or "no there has been no change"). The next sections, Sections D and E, probed the economic impact of caregiving, who in the family provided assistance with care, caregivers' attitude regarding government-sponsored services and supports, and attitudes regarding the future. Respondents circled the 5-choice option that best matched their perception. The last part of the survey asked respondents to write their biggest "gain" and "loss" as a function of providing care (open-ended questions). Table 2 shows a summary of the survey questions, excluding demographic and open-ended questions. 
Table 2: Summarized Items from The Caregivers' Perceptions Survey

\begin{tabular}{|c|c|}
\hline PART II, Section A & Section C \\
\hline Spirituality & isolation from other people has increased \\
\hline Altruism & state of health has deteriorated \\
\hline tolerance toward other people & economic standard of family has deteriorated \\
\hline peace and serenity & relations between family members have deteriorated \\
\hline faith in humanity & social life of family has deteriorated \\
\hline life optimism & feel enriched by the situation \\
\hline \multirow[t]{2}{*}{ humbleness towards what life brings } & $\begin{array}{c}\text { Section D } \\
\end{array}$ \\
\hline & who provides most care \\
\hline Section B & help from siblings \\
\hline loss of control in life & help from wider family \\
\hline feelings of depression and despair & Section $\mathbf{E}$ \\
\hline feelings of great fatigue & $\begin{array}{l}\text { I believe governmental financial support provided to families is } \\
\text { sufficient }\end{array}$ \\
\hline loss of ability to enjoy free time & $\begin{array}{l}\text { I believe persons providing care enjoy respect and recognition } \\
\text { from my country }\end{array}$ \\
\hline loss of ability to rejoice & $\begin{array}{l}\text { I believe the situation of individuals with special needs and the } \\
\text { persons providing care for them will continue to improve in my } \\
\text { country }\end{array}$ \\
\hline loss of personal life perspective & I look forward to what the future has to bring \\
\hline
\end{tabular}

\section{Results}

\section{Differences in Caregivers' Perceptions}

This research question attempted to identify similarities and differences in the stressors, perceptions and/or attitudes of caregivers from the two countries. The following are the highest percentage of responses reported for each survey item, by section.

Section A. Responding to how their level of spirituality had been influenced by caregiving, the American respondents indicated it had remained the same (48.4\%), while Czech respondents indicated that it had increased (49.3\%). Indicating how their level of altruism had been influenced, $48.4 \%$ of respondents in the United States indicated it had remained the same while $45.8 \%$ of the Czech participants indicated this. In reporting how their level of tolerance had been influenced, American respondents reported it had increased (64.5\%), while $43.1 \%$ of respondents in the Czech Republic indicated that it had increased. Indicating how their level of peace and serenity 
had been impacted, respondents in the United States expressed that it had remained the same, while $40.9 \%$ of the Czech respondents reported that peace had decreased. Responding to how their level of faith in humanity may have changed, $50 \%$ of the American respondents indicated it had remained the same, while $44.0 \%$ of respondents in the Czech Republic indicated this response. Noting how their level of life optimism had been influenced, 48.4\% of American respondents indicated it had remained the same, while $41.3 \%$ of the respondents in the Czech Republic suggested that this aspect of their life had decreased. Responding to how their level of humbleness toward what life brings, $66.7 \%$ of the Americans indicated it had increased as $41.8 \%$ of the Czech respondents reported the same.

Section B. Responding to whether they felt a loss of control in their lives, $54.8 \%$ of respondents from the United States reported that they did "sometimes", while $51.6 \%$ of respondents in the Czech Republic did not answer this question. Fifty-four percent (54.5\%) of the American respondents indicated that they "sometimes" experienced depression and despair, while the largest group of respondents in the Czech Republic (29.4\%) felt the same. No answer was given to this item by $45.3 \%$ of the Czech Republic group. Indicating if they felt fatigue, the highest percentage of respondents in the United States (45.2\%) indicated that they did "sometimes" experience fatigue while $34.7 \%$ of respondents in the Czech Republic also felt this way. In answering if they were able to enjoy free time, $38.7 \%$ of the respondents in the United States indicated that they did "sometimes", while $29.8 \%$ of respondents in the Czech Republic said "yes" they enjoyed their free time and $38.2 \%$ did not answer this question. Regarding the ability to rejoice in life, $35.9 \%$ of American respondents reported that they were not able to do this, while $24 \%$ of Czech respondents indicated that they could "sometimes". Responding to whether there had been a change in their personal life perspective, $29 \%$ of American respondents indicated "no", while $35.2 \%$ of Czech respondents reported there had been no change.

Section C. Reporting whether they perceived their isolation from people had increased as a result of caregiving, $25.8 \%$ of American respondents suggested that "yes" it had and the same number reported "no". Respondents in the Czech Republic (34.5\%) indicated that "yes" isolation has increased. Reporting whether their health had deteriorated, $35.5 \%$ of American respondents reported "no" to this question, while $25.8 \%$ of Czech respondents 
indicated that their health had "somewhat" gotten worse. In examining if the economic standard of their family had deteriorated, $29 \%$ of respondents in the United States revealed that there was "no change", while $28 \%$ of respondents in the Czech Republic indicated that their economic standing had "declined". Forty-two percent of American respondents in the United States indicated that there had been "no change" in relationships with family members, while $31.1 \%$ of respondents in the Czech Republic indicated this response. American respondents (29\%) indicated that the social life of their family had "somewhat changed" while $32 \%$ of Czech respondents revealed that "yes their social life had declined". American respondents $(38.7 \%)$ reported feeling enriched by their situation and $38.7 \%$ of the American suggested they felt "somewhat enriched". Czech respondents $(24.9 \%)$ indicated that they were not "enriched".

Section D. In responses to whom provided the most care, American respondents $(51.6 \%$ ) indicated that males and females took turns, while $73.3 \%$ of respondents in the Czech Republic indicated that the female caregiver provided the majority of care. American respondents (32.3\%) indicated the "no" siblings did not help with care, while $42.6 \%$ of respondents in the Czech Republic reported feeling this way. Indicating whether the wider family provided assistance with care, $32.3 \%$ of American respondents reported "yes", while $30.7 \%$ of Czech respondents reported "no". Figure 1 shows the ten survey items that revealed a difference in the highest percentage responses between caregivers in the United States and the Czech Republic for Sections A-D of the survey.

\section{Impact of Governmental Services and Supports on Caregivers' Perceptions}

The questions in Section E of the survey attempted to address the impact of governmental support and services on caregivers' quality of life. Responding to the question which asked if the caregiver believed that governmental financial support to families in their country was adequate, the highest percentage of respondents in the United States (41.9\%) indicated that they believed that was the case, while the highest percentage of respondents in the Czech Republic (35.6\%) indicated that they did not believe support was adequate. Responding to whether caregivers are given respect and recognition in their country, $75.8 \%$ of American respondents indicated "yes", while $24.8 \%$ of the respondents in the Czech Republic indicated a "rather no" to 


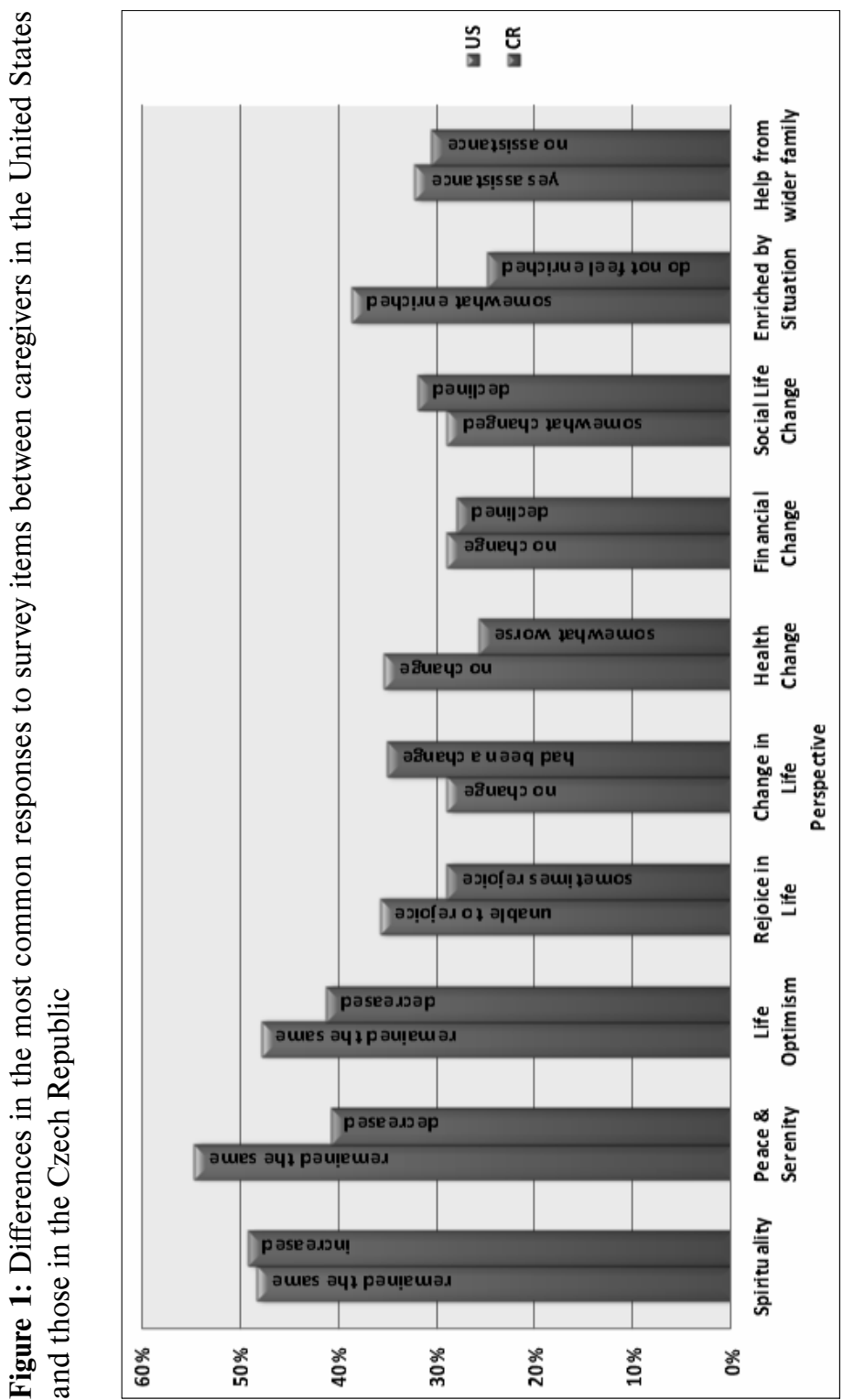


this item. When asked if caregivers believed that the situation for individuals with special needs and the persons who provided their care will continue to improve in their country, $29 \%$ of the American respondents indicated "somewhat yes", while $36 \%$ of respondents in the Czech Republic indicated that they "did not know". When asked if caregivers looked forward to what the future would bring, $29.6 \%$ of the respondents in the United States indicated "absolutely", while $38.8 \%$ of Czech caregivers reported they "were afraid of the future". Figure 2 shows the highest percentage responses to survey items that addressed governmental support and services in the two countries.

Figure 2: Differences in caregivers' most common survey responses to governmental support and services survey items in the United States and Czech Republic

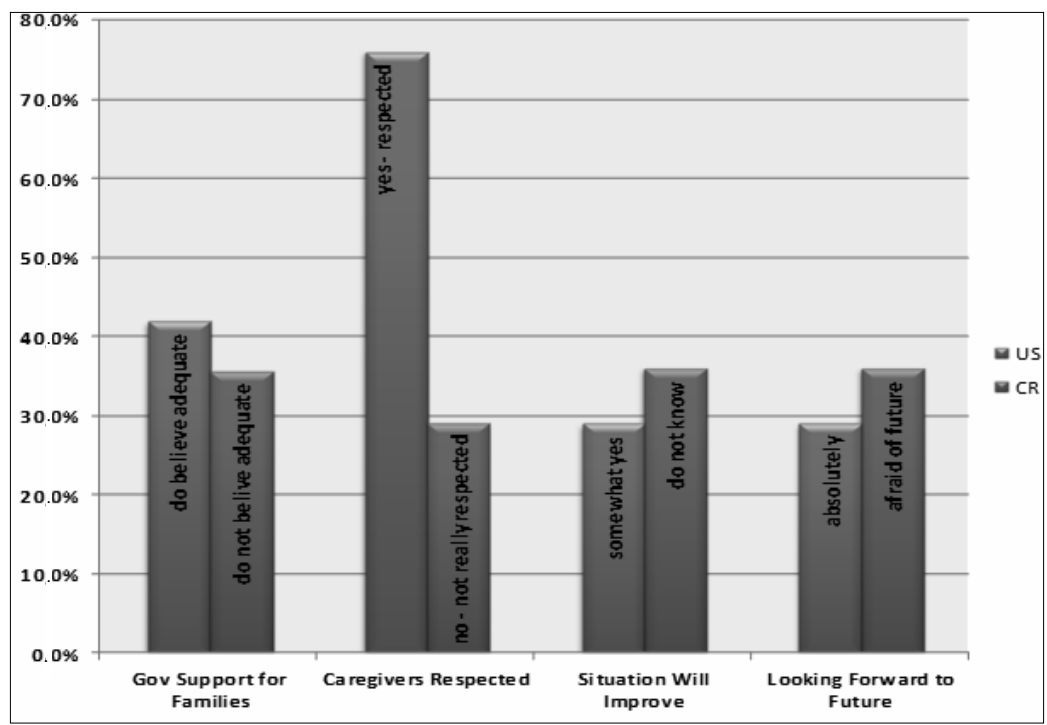

\section{Qualitative Responses}

This part of the survey allowed respondents to express their opinion in two open-ended questions. The first question asked caregivers to indicate their three "greatest gains from providing care" and the second asked for three "greatest losses from providing care". Responses were clustered by topic and 
percentages calculated. Fifty-eight percent of the American caregivers indicated their most common gain from caregiving involved a renewed positive perspective on life and joy from observing the family member with a disability learn new skills. The largest number of caregivers in the Czech Republic identified their greatest gain to involve "personal gains" such as positive emotions and feelings (31.9\%). When identifying their greatest losses from being a caregiver, American respondents most frequently reported strained relationships within and outside the family and a reduction in social or personal time ( $43 \%)$ and others (32\%) commented on the financial strain of caring for a family member with a disability. Similarly, respondents in the Czech Republic reported their most common loss as a loss of personal free$\operatorname{dom}(30.1 \%)$.

\section{Discussion}

This study found that caregivers of individuals with intellectual disabilities in the United States and the Czech Republic reported similarities and differences in their responses to a survey designed to explore perceptions of their lives, their family's life, caregiving responsibilities and their country's willingness to support them and their family member with special needs. In looking at the similarities, caregivers in both the United States and the Czech Republic revealed that their caregiving experiences had increased their feelings of humbleness toward what life brings and their tolerance of others. Both groups indicated that they believed that the isolation of their family had increased, and that they sometimes experienced great fatigue. The majority of respondents, in both countries, reported that their sense of altruism, faith in humanity, and their relationships with family members had remained the same as an outcome of providing care. Further, most respondents noted that their greatest gain from caregiving involved positive personal feelings of enrichment and an increased positive personal perspective.

Several differences were revealed when survey responses were compared. For example, caregivers in the United States noted that their sense of peace and serenity and feeling of life optimism had remained the same while these feelings were described as decreased by caregiving responsibilities by the Czech caregivers. The majority of American caregivers revealed that they were unable to rejoice in life, but Czech caregivers reported being able to do this only sometimes. Spirituality was reported as remaining the same by the 
Americans and as increased by the Czech group. In terms of their personal life perspective, most American caregivers indicated they did not experience a loss of this while Czech caregivers indicated that their life perspective had been negatively influenced by their responsibilities of caregiving. American respondents reported that their health had not been affected, but Czech caregivers noted their health had been "somewhat" affected. Life optimism was reported as remaining the same for the majority of American caregivers, yet was reported as decreased for most Czech care providers. While the family's social life was reported as "somewhat" worse because of caregiving demands by the American group, the Czech group indicated that their social life as a family was indeed worse. Most of the U.S. caregivers indicated that they felt "somewhat" enriched by their situation while the Czech group commented they did not feel enriched by caregiving tasks.

It seems clear that cultural differences account for some of the differences found. For instance, respondents in the United States indicated that both the male/father figure and female/mother figure in the home took turns providing care $(52 \%)$. In contrast, women were reported as the principal caregivers in the Czech Republic (73\%). Family practices in the United States, as a general rule, may be described as more egalitarian in terms of parental child rearing responsibilities than those in the Czech Republic so this outcome may not be surprising. Interestingly, most of the American and Czech caregivers noted that siblings did not provide significant assistance with caregiving of family members with disabilities in their families (U.S. $33 \%$; C.R. $47 \%$ ). But, American caregivers revealed that extended family members were helpful. Most Czech caregivers noted that extended family members were not helpful. Having shared parenting and caregiving responsibilities, as well as assistance from individuals outside the nuclear family, would seem to have a strong positive influence on the quality of life of caregivers living in the United States. It may be that American extended family members and others outside the family are more willing to provide assistance because there is less stigma associated with intellectual disabilities in that country. For nearly forty years, governmental services and inclusion into nearly all aspects of daily life have been commonplace in the United States. For this reason, immediate family members may be more willing to seek assistance from extended family members (Sandler, Warren, \& Raver, 1995), and extended family members may be more willing to provide it. 
It was uncommon for the American respondents in this study to omit answering a survey item. However, respondents from the Czech Republic did not answer about $20 \%$ of the items and occasionally, no answer was the most common response to an item. The omitted items tended to be those that dealt with what may be described as more personal information such as one's ability to enjoy free time, feelings of depression and despair, feelings of loss of control and the ability to rejoice in life. It may be the caregivers in the Czech Republic, who have enjoyed a shorter history of freedom of speech, may have felt less comfortable answering these questions, fearing formal or informal reprisals to their child or family.

\section{General Implications}

In general, the caregivers in the Czech Republic may be characterized as slightly less positive in their outlook than the American caregivers since they reported a decrease in life optimism, less ability to enjoy free time, and that they did not feel enriched by providing care for an individual with special needs. American caregivers noted that they felt respected and acknowledged while those in the Czech Republic did not which undoubtedly affected the Czech respondents' perception of their quality of life. It may be that these findings may also be an outcome of the populations to whom caregivers were providing care. That is, the majority of Czech caregivers were providing care to individuals who they described as falling into the severe-profound mental retardation range while the majority of those receiving care in the United States were described as functioning within the mild-moderate range of intellectual disabilities. It would follow that providing care to individuals with lower levels of personal independence could be more physically draining and demanding, fostering less positive perceptions. Additionally, the individuals receiving care in the Czech Republic tended to be older than those in the United States.

Several factors affect the degree to which the results of this study may be generalized. First, respondents from the United States resided in the same geographical area and were a small sample; those in the Czech Republic represented families from across the country. Second, the majority of the respondents were female. Third, a large portion of the respondents were married or lived with a partner that may have influenced their responses. Finally, although most individuals receiving care were below the age of 20 , 
different results may have been generated if all family members had been of similar age and received comparable services. More research is needed which evaluates caregivers' quality of life issues and seeks to develop and identify family-centered supports that may promote the coping capacities of caregivers based on these evaluations. Further, future research needs to focus on the development of standardized evaluation tools which may give caregivers, and other constituents, a voice in shaping the services provided. This is particularly critical in countries in which parents and family members have fewer rights.

The caregivers in this study made it clear that caring for an individual with an intellectual disability presented rewards as well as difficulties. This outcome has been reported by others in the United States (Grant \& Whittell, 2000; Heiman, 2002; Judge, 1998). The results of the present study suggest that although caregivers in the two countries reported many strong feelings such as increased fatigue, the majority in both countries were also able to appreciate the positive aspects associated with their caregiving responsibilities such as increased humbleness. Equally informative is that both groups revealed similar advantages (e.g., increased positive personal feelings) and disadvantages from providing care (e.g., loss of personal and family freedom and disruption in family relationships). Bailey and colleagues (1998) and others (e.g., Purcell, Turnbull, \& Jackson, 2006; Wallender, Schmidt, \& Koot, 2001) have asserted that family quality of life should be used as a determinant of the appropriateness of services governments and service providers offer families. In the past in the United States, services have been based on lawmakers' best guesses and informal polling of the stakeholders. Attempting to gather more quantifiable data from stakeholders should increase the government's ability to make informed decision-making.

It is generally accepted that being a caregiver of an individual with a disability can involve time, energy, and frequent disruption of family routines, particularly when health concerns are involved (Floyd \& Gallagher, 1997; Murphy et al., 2006; Schultz \& Quitner, 1998). Parish and associates (2008), in reporting data from a national survey conducted in the United States, found more material hardship among families raising children with disabilities when they were compared to families raising typical children, primarily due to the costs of therapies and loss of income. The Parish study and this one suggest that current government services and programs may be 
inadequate in addressing the material, emotional and relationship-based hardships experienced by families. Although more research is needed to identify the specific strains families face, it is evident that caregivers need personalized supports to assist them in managing and meeting the needs of the individuals with a disability for whom they are providing care.

\section{References}

Bailey, D., McWilliams, R., Darkes, L., Hebbeler, K., Simeonsson, R., Spiker, D., et al., (1998). Family Outcomes in Early Intervention: A Framework for Program Evaluation and Efficacy Research. Exceptional Children, 62, 313-328.

Brooke, V., \& McDonough, J. T. (2008). The Facts Ma'am, Just the Facts: Social Security Disability Benefit Programs and Work Incentives. Teaching Exceptional Children, 41(1), 58-65.

Emerson, E. (2003). Mothers of Children and Adolescents with Intellectual Disability: Social and Economic Situation, Mental Health Status, and the Self-assessed Social and Psychological Impact of the Child's Difficulties. Journal of Intellectual Disability Research, 47, 385-399.

Ferrell, C., Brooke, V., Kregel, J., \& Getzel, E. (Eds). (2002). Get a Job! How Employment Affects Your Supplemental Security Income and Medicaid Benefits. Richmond, VA: Virginia Commonwealth University, Benefits Assistance Resource Center.

Florian, V., \& Findler, L. (2001). Mental Health and Marital Adaptation among Mothers of Children with Cerebral Palsy. American Journal of Orthopsychiatry, 71(3), 358-367.

Floyd, F. J., \& Gallagher, E. M. (1997). Parental Stress, Care Demands, and Use of Support Services for School-age Children with Disabilities and Behavior Problems. Family Relations, 46, 359-371.

Gallagher, P., Fialka, J., Rhodes, C., \& Arceneaux, C. (2003). Working with Families: Rethinking Denial. Young Exceptional Children, 5(2), 11-17.

Grant, G., \& Whittell, B. (2000). Differentiated Coping Strategies in Families with Children or Adults with Intellectual Disabilities: The Relevance of Gender, Family Composition and the Life Span. Journal of Applied Research in Intellectual Disabilities, 13, 256-275.

Harden, J. (2005). Parenting a Young Person with Mental Health Problems: Temporal Disruption and Reconstruction. Sociology of Health and Illness, 27(3), 351-371. 
Heiman, T. (2002). Parents of Children with Disabilities: Resilience, Coping and Future Expectations. Journal of Developmental and Physical Disabilities, 14(2), 159-171.

Individuals with Disabilities Education Improvement Act (IDEIA) (2004). Public Law No. 108-446; United States of America.

Judge, S. L. (1998). Parental Coping Strategies and Strengths in Families of Young Children with Disabilities. Family Relations, 47(3), 263-268.

King, G., King, S., Rosenbaum, P. \& Goffin, R. (1999). Family-centered Caregiving and Well-being of Parents of Children with Disabilities: Ling Process to Outcome. Journal of Pediatric Psychology, 24, 41-53.

Legislation for Individuals with Special Needs (1993). Constitution of the Czech Republic (Ústava České Republiky), No 1/1993.

Linan-Thompson, S., \& Jean, R. (1997). Completing the Parent Participation Puzzle: Accepting Diversity. TEACHING Exceptional Children, 30(2), 46-50.

Maes, B., Broekman, T. G., Dosen, A., \& Nauts, J. (2003). Caregiving Burden of Families Looking after Persons with Intellectual Disability and Behavioural or Psychiatric Problems. Journal of Intellectual Disability Research, 47(6), 447-455.

McDonald, T. J., Poertner, J., \& Pierpoint, J. (1999). Predicting Caregiver Stress: An Ecological Perspective. American Journal of Orthopsychiatry, 69(1), 100-109.

Murphy, N. A., Christian, B., Caplin, D. A., \& Young, P. C. (2006). The Health of Caregivers for Children with Disabilities: Caregiver Perspectives. Child Care Health and Development, 33(2), 180-187.

National Plan for Increasing Opportunities for People with Disabilities (1998). (Národní plán pro vyrovnávání příležitostí pro občany se zdravotním postižením). Czech Republic Resolution No. 256, April 14.

Parish, S. L., Rose, R. A., Grinstein-Weiss, M., Richman, E. L., \& Andrews, M. E. (2008). Material Hardship in U.S. Families Raising Children with Disabilities. Exceptional Children, 75(1), 71-92.

Park, J., Hoffman, L., Marquis, J., Turnbull, A., P., Poston, D., Mannan, H., et al. (2003). Toward Assessing Family Outcomes of Service: Validation of a Family Quality of Life Survey. Mental Retardation, 41(5), 367-385. 
Plant, K. M., \& Sanders, M. R. (2007). Predictors of Care-giver Stress in Families of Preschool-aged Children with Developmental Disabilities. Journal of Intellectual Disability Research, 51(2), 109-124.

Purcell, M., Turnbull, A., \& Jackson, C. (2006). Linking Early Childhood Inclusion and Family Quality of Life: Current Literature and Future Directions. Young Exceptional Children, 9(3), 10-19.

Raver, S. (2009). Early Childhood Special Education (0-8 Years): Strategies for Positive Outcomes. Upper River Saddle, NJ: Pearson/Merrill/Prentice Hall. Raver, S. A. (2005). Using Family-based Practices for Young Children with Special Needs in Preschool Programs. Childhood Education, 82(1), 9-13. Raver, S., Michalek, A., \& Simpson, A. (2009). Major Stressors and Life Goals of Caregivers of Individuals with Disabilities. Unpublished manuscript.

Raina, P., O’Donnell, M., Rosenbaum, P., Brehault, J., Walter, S. D., Russell, D., et al. (2005). The Health and Well-being of Caregivers of Children with Cerebral Palsy. Pediatrics, 115(6), 626-636.

Raina, P., O’Donnell, M., Schwellnus, H., Rosenbaum, P., King, G., Brehaut, J., et al. (2004). Caregiving Process and Caregiver Burden: Conceptual Models to Guide Research and Practice. BMC Pediatrics, 4, 1471-2431.

Rosenzweig, J. M., Brennan, E. M., \& Ogilvie, A. M. (2002). Work-family Fit: Voices of Parents of Children with Emotional and Behavioral Disorders. Social Work, 47(4), 415-424.

Social Security Administration (2007). Benefits for Children with Disabilities. Baltimore: Author.

Special Needs Education in the Czech Republic (2000). Retrieved April 3, 2009, from http://www.european-agency.org.

Special Needs Education with the Educational System: Czech Republic (n.d.).

Retrieved April 4, 2009, from http://www.euroeducation.net.

Sandler, A., Warren, S., \& Raver, S. (1995). Grandparents as a Source of Support for Parents of Children with Disabilities. Mental Retardation, 33, 248-250.

Schultz, R., \& Quittner, A. (1998). Caregiver of Children and Adults with Chronic Illness Conditions: Introduction to the Special Issue. Health Psychology, 17, 107-111.

Turnbull, A., Turnbull, R., Erwin, E., \& Soodak, L. (2006). Families and Exceptionality ( $5^{\text {th }}$ ed.). Upper Saddle River, NJ: Pearson/Merrill/Prentice Hall. 
Wallender, J., Schmidt, M., \& Koot, H. (2001). Quality of Life Measures in Children and Adolescents: Issues, Instruments, and Applications. Journal of Clinical Psychology, 57(4), 571-585.

White, N., \& Hastings, R. P. (2004). Social and Professional Support for Parents of Adolescents with Severe Intellectual Disabilities. Journal of Applied Research in Intellectual Disabilities, 17, 181-190. 